\title{
PENGARUH VARIASI PH TERHADAP KADAR FLAVONOID PADA EKSTRAKSI PROPOLIS DAN KARAKTERISTIKNYA SEBAGAI ANTIMIKROBA
}

\author{
Suci Nurfazri Rismawati ${ }^{1}$, Ismiyati ${ }^{2}$ \\ ${ }^{1}$ Jurusan Teknik Kimia, FakultasTeknik, UniversitasMuhammadiyah Jakarta \\ sucinurfazri@gmail.com
}

\begin{abstract}
ABSTRAK
Propolis telah dikenal dikalangan masyarakat sebagai obat, dan makanan kesehatan. Propolis merupakan zat resin yang dikumpulkan oleh lebah madu (stingless bee dan honey bee) dari berbagai tanaman yang memiliki khasiat seperti antimikroba, antioksidan, induksi apoptosis dan anti kanker. Propolis adalah substansi resin keras, maka diperlukan adanya proses ekstraksi untuk mendapatkan propolis yang siap dikonsumsi. Tujuan penelitian ini adalah untuk menganalisa pengaruh variasi $\mathrm{pH}$ terhadap proses ekstraksi propolis dengan pelarut air dan karakterisasinya sebagai zat antimikroba. Ekstraksi dilakukan dengan teknik maserasi, dengan perbandingan bubuk propolis dan pelarut adalah 2:8, dengan variasi $\mathrm{pH}$ 2,4,6,8 dan 10. Flavonoid diukur dengan metode kolorimetri kompleksasi aluminium - flavonoid. Aktivitas antimikroba terhadap Staphylococcus aureus diukur dengan metode difusi disk dan pembentukan zona hambatan. Dari deret standar didapatkan hasil regresi sebesar 0,9995 dan kandungan flavonoid tertinggi didapatkan dengan menggunakan pelarut air pH 8 yaitu sebesar 62,6098 ppm. Aktifitas antibakteri dari propolis menunjukan hasil positif membentuk zona hambat pada pelarut air $\mathrm{pH} 8$ yaitu sekitar 2,0 mm. Didapatkan persamaan persamaan garis linearnya yaitu $y=5,6029 x-4,2001$ dengan nilai dengan $R^{2}$ adalah 0,8289 . Kadar flavonoid optimum ditunjukkan pada ekstraksi pada $\mathrm{pH} 8$
\end{abstract}

Kata kunci :aktivitas antimikroba, flavonoid, $\mathrm{pH}$, propolis

\begin{abstract}
Propolis has been recognized among people as a medicine, and health food. Propolis is a resin substance collected by honey bee from various plants that have properties such as antimicrobials, antioxidants, apoptosis and anti-cancer. Propolis is a hard resin substance, it needs an extraction process to get propolis ready for consumption. The purpose of this study was to analyze the influence of $\mathrm{pH}$ variation on the extraction process of propolis with water solvent and its characterization as an antimicrobial agent. The extraction was done by maceration technique, with the ratio of propolis powder and solvent was 2: 8, with variation of $\mathrm{pH} 2,4,6,8$ and 10. Flavonoids were measured by colorimetric complexation method of aluminum - flavonoids. Antimicrobial activity against Staphylococcus aureus was measured by the disk diffusion method and the formation of the inhibitory zone. From the standard series obtained regression of 0.9995 and the highest flavonoid content obtained by using water solvent $\mathrm{pH} 8$ which is equal to $62.6098 \mathrm{ppm}$. Antibacterial activity of propolis showed positive result form resistor zone on water solvent $\mathrm{pH} 8$ which is about $2.0 \mathrm{~mm}$. The linear equation equation equation is $y=5,6029 x-4,2001$ with with $R 2$ is 0,8289 . The optimum flavonoid content is indicated on the extraction at $\mathrm{pH} 8$
\end{abstract}

Keywords: antimicrobial activity, flavonoids, $\mathrm{pH}$, propolis 


\section{PENDAHULUAN}

Propolis adalah zat resin yang dihasilkan dari tunas, daun dan eksudat pohon dan tanaman yang tercampur dengan serbuk sari, lilin dan enzim kemudian disekresikan oleh lebah jenis lebah Trigona sp. Propolis berwarna hijau tua atau coklat tua dengan rasa yang pahit memiliki beberapa karakteristik penting seperti efek antimikroba dan antioksidan, sifat anestesi dan lain-lain. Karena karakteristik inilah, telah menarik perhatian masyarakat dalam beberapa tahun terakhir sebagai zat penting yang dapat digunakan dalam bahan makanan, minuman, kosmetik dan obat-obatan untuk meningkatkan kesehatan dan mencegah penyakit. Propolis adalah substansi resin keras, maka diperlukan adanya proses ekstraksi untuk mendapatkan propolis yang siap dikonsumsi

Ekstrak propolis mengandung senyawa golongan flavonoid, fenol, triterpenoid, monodan siskuiterpen, tanin, dan alkaloid. Flavonoid merupakan salah satu konstituen yang paling penting dapat mewakili sekitar $50 \%$ kandungan dari propolis. Kandungan flavonoid tergantung pada daerah mana propolis tersebut dikumpulkan, karena karakteristiknya dipengaruhi oleh tanaman, faktor geografis dan cuaca. Senyawa flavonoid merupakan senyawa yang larut dalam air, memiliki aktivitas antioksidan sehingga, propolis bisa menjadi zat antibakteri, antivirus, dan antijamur. Aktivitas antibakteri dari ekstrak propolis dapat menghambat pertumbuhan bakteri stappylococcus (Hasan dkk, 2013)

Pengaruh $\mathrm{pH}$ selama ekstraksi propolis berpengaruh pada hasil kandungan flavonoid nya. Terdapat tiga ukuran yang menunjukan kepolaran suatu pelarut yaitu momen dipol, konstanta dielektrik dan kelarutannya dengan air. Molekul dari pelarut dengan momen dipol yang besar dan konstanta dielektrik yang tinggi termasuk polar. Menurut Mello dkk, (2006), air merupakan pelarut yang paling polar dengan konstanta dielektrik sebesar 80 , dengan adanya variasi $\mathrm{pH}$ pada pelarut air yang digunakan maka polaritas air sedikit menurun sehingga dapat mengekstrak tidak hanya senyawa polar dalam propolis tetapi juga senyawa semi polarnya.

Tujuan penelitian ini adalah untuk mengevaluasi efek dari variasi $\mathrm{pH}$ terhadap hasil ekstraksi propolis, dengan menggunakan pelarut air. Serta menganalisa uji kandungan flavonoid dalam ekstrak propolis optimal. Selain itu, dilakukan analisis untuk mengetahui karakteristik propolis sebagai anti bakteri, terutama terhadap bakteri stappylococcus.

\section{METODE}

Metode yang digunakan adalah metode ekstraksi maserasi. Digunakan metode maserasi karena propolis memiliki sifat termostabil dengan titik didih $60^{\circ} \mathrm{C}$ $65^{\circ} \mathrm{C}$ sehingga metode maserasi tepat digunakan untuk mengekstrak propolis karena tidak menggunakan suhu tinggi, dan peralatan yang digunakan pun cukup sederhana. Pelarut yang digunakan adalah air, dibantu $\mathrm{HCl}$ dan $\mathrm{NaOH}$ untuk mengatur $\mathrm{pH}$. Perbandingan bubuk propolis dan pelarut adalah 2:8. Kemudian dimasukan ke dalam waterbath pada suhu $45^{\circ} \mathrm{C}$ selama 10 menit dan disimpan selama 5 hari pada kondisi gelap dan setiap harinya dilakukan pengocokan. Pada hari ke-5 sampel di centrifuge selama 20 menit pada kecepatan 8800 rpm , kemudian di filtrasi dan disimpan pada suhu $4^{\circ} \mathrm{C}$ selama semalam kemudian filtrate difiltrasi kembali untuk mengurangi kandungan lilin dalam ekstrak. Pelarut air dengan variasi $\mathrm{pH}$ diatur dengan menambahkan larutan $\mathrm{HCl}$ $1 \mathrm{~N}$ untuk menurunkan $\mathrm{pH}$ dan $\mathrm{NaOH} 1 \mathrm{~N}$ untuk menaikan $\mathrm{pH}$ sehingga $\mathrm{pH}$ selama ekstraksi stabil.

Sedangkan metode analisa kadar flavonoid menggunakan alat spektrofotometer UV-VIS pada panjang gelombang 434,2 nm, dan menggunakan pereaksi $\mathrm{AlCl}_{3}$. Langkah pertama yang dilakukan adalah membuat deret standar menggunakan standar quercetin untuk mendapatkan nilai slope (b) dan intersep (a) nya. Kemudian melakukan pengujian flavonoid pada sampel sebanyak 3 kali pengujian, agar didapatkan nilai abs dari masing-masing sampel, setelah itu dapat dihitung kadar total flavonoid dalam sampel (f) dengan menggunakan rumus sebagai berikut :

Keterangan

$$
f=\frac{a b s-a}{b}
$$

Abs = Absorbansi sampel

$\mathrm{f}=$ Kadar total flavonoid sampel $(\mu \mathrm{g} / \mathrm{mL})$

$\mathrm{a}=$ Intersep dari kurva standar

$\mathrm{b}=$ Slope dari kurva standar

Untuk pengujian aktivitas daya antimikroba digunakan Metode cakram kertas yaitu meletakkan cakram kertas 
yang telah direndam dalam larutan uji di atas media padat yang telah diinokulasi dengan bakteri. Setelah diinkubasi, pertumbuhan bakteri diamati untuk melihat ada tidaknya daerah hambatan disekeliling cakram.

\section{Diagram Alir Penelitian}

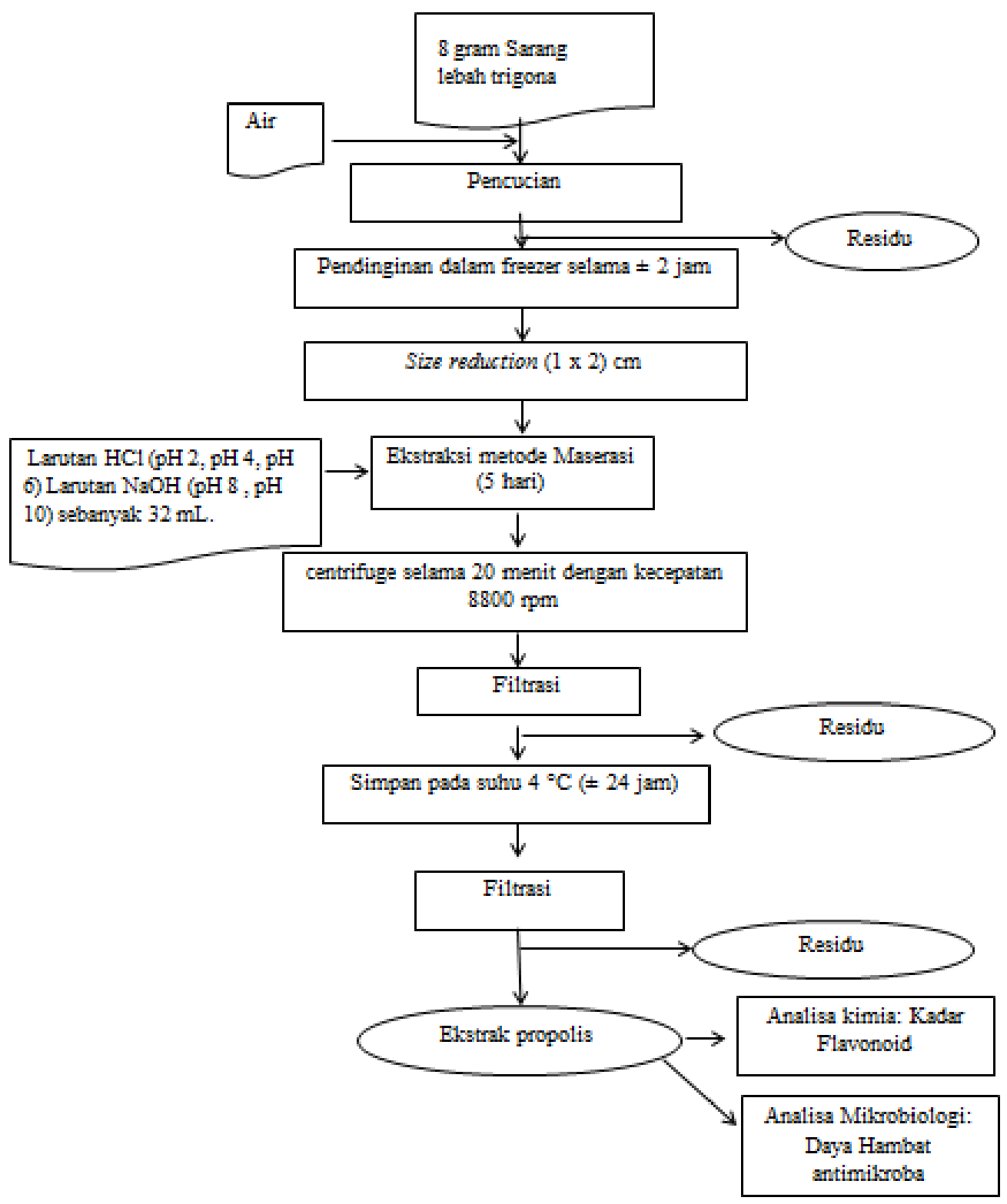

Gambar 1. Diagram Alir Proses Ekstraksi Propolis

\section{HASIL DAN PEMBAHASAN}

Ekstrak propolis diperoleh dari hasil ekstraksi sarang lebah Trigona $s p$ menggunakan metode maserasi dengan variasi $\mathrm{pH} 2, \mathrm{pH} \mathrm{4,} \mathrm{pH} 6, \mathrm{pH} 8, \mathrm{pH} 10 . \mathrm{Uji}$ visual dengan cara mengamati hasil ekstrak yang di hasilkan. Pada ekstrak propolis $\mathrm{pH} 2$ dan $\mathrm{pH} 4$ memiliki warna yang sama yaitu coklat muda, sedangkan ekstrak propolis $\mathrm{pH} 6, \mathrm{pH} 8$, dan $\mathrm{pH} 10$ memiliki warna coklat yang lebih pekat. Hasil pengukuran absorbansi sampel dengan metode $\mathrm{AlCl}_{3}$ dan menggunakan alat Spektofotometri UV-Visible, disajikan pada Tabel 1 
Tabel 1. Data absorbansi sampel

\begin{tabular}{|c|c|c|c|}
\hline Pelanut & \multicolumn{3}{|c|}{ Absorbansi (Abs) } \\
\hline & Uji 1 (abs) & Uji 2 (abs) & Uji 3 (abs) \\
\hline pH 2 & 0,089 & 0,074 & 0,092 \\
\hline $\mathrm{pH} 4$ & 0,112 & 0,111 & 0,116 \\
\hline $\mathrm{pH} 6$ & 0,191 & 0,168 & 0,182 \\
\hline $\mathrm{pH} 8$ & 0,427 & 0,408 & 0,446 \\
\hline $\mathrm{pH} 10$ & 0,415 & 0,315 & 0,409 \\
\hline
\end{tabular}

Hasil pengukuran absorbansi deret standar quercetine dengan metode $\mathrm{AlCl}_{3}$ dan menggunakan alat Spektofotometri UV-Visible disajikan pada Tabel 2 dan Gambar 2

Tabel 2. Deret standar quersetine

\begin{tabular}{|c|c|c|}
\hline Konsentrasi & Absorbansi (abs) & Rata-rata(abs) \\
\hline \multirow{3}{*}{$10 \mathrm{ppm}$} & 0,068 & \multirow{3}{*}{0,0687} \\
\hline & 0,069 & \\
\hline & 0,069 & \\
\hline \multirow{3}{*}{$20 \mathrm{ppm}$} & 0,158 & \multirow{3}{*}{0,158} \\
\hline & 0,158 & \\
\hline & 0,158 & \\
\hline \multirow{3}{*}{40 ppm } & 0,293 & \multirow{3}{*}{0,293} \\
\hline & 0,293 & \\
\hline & 0,293 & \\
\hline \multirow{3}{*}{$60 \mathrm{ppm}$} & 0,423 & \multirow{3}{*}{0,423} \\
\hline & 0,423 & \\
\hline & 0,423 & \\
\hline \multirow{3}{*}{$80 \mathrm{ppm}$} & 0,571 & \multirow{3}{*}{0,571} \\
\hline & 0,571 & \\
\hline & 0,571 & \\
\hline \multirow{2}{*}{$100 \mathrm{ppm}$} & 0,706 & \multirow{2}{*}{0,706} \\
\hline & $\begin{array}{l}0,706 \\
0,706\end{array}$ & \\
\hline
\end{tabular}

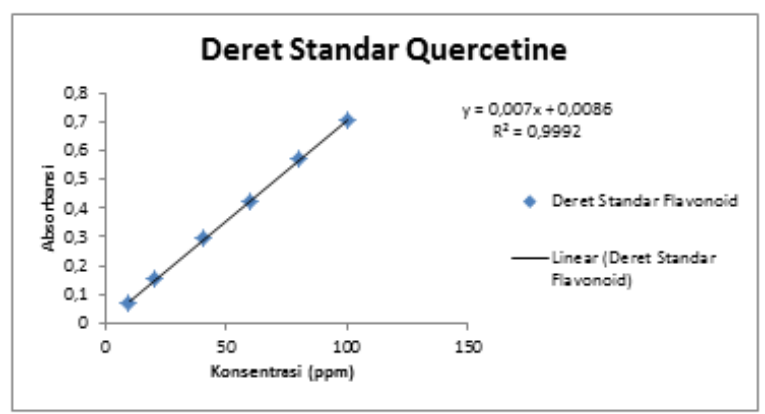

Gambar 2.Kurva deret standar quersetine

Dari kurva deret standar quersetine tersebut maka dapat dihitung nilai slope (b) dan intersep (a) nya. Nilai slope (b) yang didapatkan sebesar 0,007 dan intersep (a) nya sebesar 0,0086 serta $R^{2}$ sebesar 0,9992 . Maka setelah dihitung menggunakan rumus perhitungan kadar flavonoid didapatkan hasil sebagai berikut
Tabel 3. Kadar flavonoid pada masingmasing kondisi $\mathrm{pH}$

\begin{tabular}{|l|r|r|r|c|}
\hline \multicolumn{1}{|c|}{ Pelarut } & \multicolumn{4}{|c|}{ Kadar Flavonoid (ppm)/ml } \\
\hline $\mathrm{XH})$ & $\begin{array}{c}\text { Uji 1 } \\
(\mathrm{Y})\end{array}$ & $\begin{array}{c}\text { Uji 2 } \\
(\mathrm{Y})\end{array}$ & $\begin{array}{c}\text { Uji 3 } \\
(\mathrm{Y})\end{array}$ & $\begin{array}{c}\text { Rata-rata } \\
(\mathrm{Y})\end{array}$ \\
\hline $\mathrm{pH} 4$ & 11,4924 & 9,3475 & 11,9214 & 10,92045 \\
\hline $\mathrm{pH} 6$ & 14,7813 & 12,8619 & 13,4412 & 13,69482 \\
\hline $\mathrm{pH} 8$ & 26,0778 & 19,4666 & 21,0889 & 22,21113 \\
\hline $\mathrm{pH} 10$ & 59,8244 & 47,2761 & 51,6793 & 52,92668 \\
\hline & 58,1085 & 36,5000 & 47,3920 & 47,33354 \\
\hline
\end{tabular}

Dari data tabel diatas dapat dicari regresi linear dari pengaruh variasi $\mathrm{pH}$ terhadap kadar flavonoid dengan memplotkan nilai $\mathrm{pH}$ pada sumbu $\mathrm{x}$ dan memplotkan kadar flavonoid pada sumbu $y$, yang disajikan pada Gambar 3 .

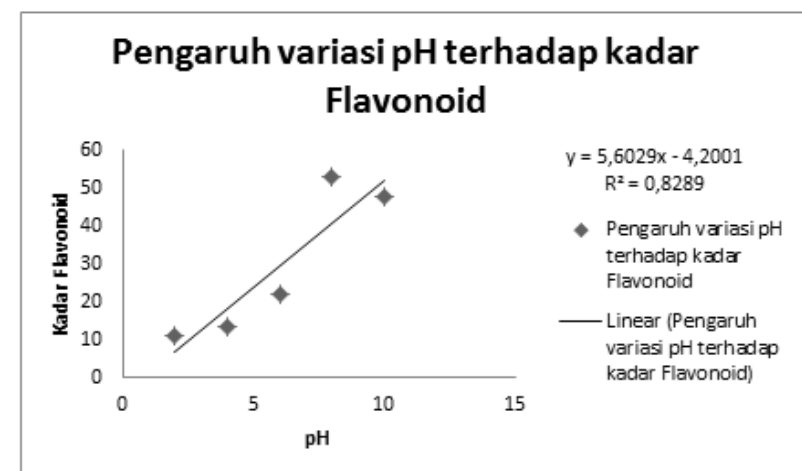

Gambar 3.Hubungan variasi $\mathrm{pH}$ dan kadar Flavonoid

Dari kurva pengaruh variasi $\mathrm{pH}$ terhadap kadar Flavonoid tersebut maka dapat dilihat persamaan garis linearnya yaitu $y=5,6029 x-4,2001$ dengan nilai slope (b) yang didapatkan sebesar 5,6029 dan intersep(a) nya sebesar - 4,2001. Dan regresinya $\left(R^{2}\right) \quad 0,8289$. Dari kurva diatas juga menunjukan hasil positif karena dengan bertambahnya nilai $\mathrm{pH}$ maka nilai kadar flavonoid semakin meningkat terkecuali pada kondisi $\mathrm{pH} 10$.

Hasil penelitian ini dapat diketahui ekstrak propolis yang memiliki warna yang paling gelap adalah adalah pada $\mathrm{pH} 10$, namun setelah dilakukan analisa kadar flavonoid ternyata ekstrak propolis yang memiliki kadar paling tinggi justru pada $\mathrm{pH} 8$, meskipun perbedaan kadar flavonoid pada $\mathrm{pH} 8$ dan $\mathrm{pH}$ 10 tidak terlalu berbeda, Hal tersebut disebabkan oleh perbedaan konstanta dielektrik pada variasi $\mathrm{pH}$ air yang digunakan untuk ekstraksi propolis. Semakin tinggi $\mathrm{pH}$ air maka semakin menurun polaritasnya, hal tersebut dapat diketahui dari konstanta dielektriknya. Hasil kadar flavonoid pada 
ekstrak $\mathrm{pH} 10$ menunjukan penurunan bila dibandingkan dengan ekstrak $\mathrm{pH}$ 8, Hal tersebut dikarenakan penurunan polaritas air cukup signifikan pada $\mathrm{pH} 10$ sehingga menyebabkan ada senyawa polar dalam propolis yang tidak bisa terekstrak dan menyebabkan kadar flavonoid menurun. Data yang terjadi menunjukan bahwa senyawa terbanyak dalam propolis dapat terekstrak dengan baik dengan pelarut yang memiliki konstanta dielektrik atau kepolaran yang sesuai. Pengukuran kadar flavonoid total menggunakan metode spektrofotometri sesuai yang dilakukan oleh Mihai (2010). Prinsip dari metode ini adalah terbentuknya kompleks $\mathrm{AlCl}_{3}$ dengan flavonoid yang menghasilkan reaksi warna. Pereaksi $\mathrm{AlCl}_{3}$ hanya dapat digunakan untuk mendeteksi flavonoid dengan gugus orto dihidroksi dan hidroksi karbonil atau yang hanya memiliki gugus orto dihidroksi saja.

Dilakukan uji anova untuk mengetahui ada tidaknya perbedaan kadar flavonoid dalam ekstrak propolis dengan variasi $\mathrm{pH}$. Dasar pengambilan keputusan dalam analisa adalah jika nilai probabilitas signifikasi > 0,05 maka tidak terdapat perbedaan yang signifikan terhadap kadar flavonoid yang terkandung dalam ekstrak propolis dan juga daya hambat terhadap mikroba dengan ekstraksi menggunakan berbagai pelarut dan variasi $\mathrm{pH}$. Sedangkan jika nilai probabilitas signifikasi $<$ 0,05 maka terdapat perbedaan yang signifikan terhadap kadar flavonoid yang terkandung dalam ekstrak propolis. Uji anova atau analisis varian terhadap lima kondisi sampel berbeda $\mathrm{pH}$, serta dilakukan 3 replikasi didapatkan hasil :

Tabel 4. Hasil perhitungan Anova

\begin{tabular}{|l|c|r|r|r|}
\hline \multicolumn{1}{|c|}{ Pelarut air } & Pengulangan & Jumlah & Rata-rata & \multicolumn{1}{c|}{ Varian } \\
\hline $\mathrm{pH} 2$ & 3 & 32,76136 & 10,92045 & 1,901603 \\
\hline $\mathrm{pH} 4$ & 3 & 41,08447 & 13,69482 & 0,969237 \\
\hline $\mathrm{pH} 6$ & 3 & 66,6334 & 22,21113 & 11,87148 \\
\hline $\mathrm{pH} 8$ & 3 & 158,7801 & 52,92668 & 40,5318 \\
\hline $\mathrm{pH} 10$ & 3 & 142,0006 & 47,33354 & 116,735 \\
\hline
\end{tabular}

Tabel 5. Hasil perhitungan Anova varian

\begin{tabular}{|l|c|r|c|c|c|c|}
\hline $\begin{array}{l}\text { Source of } \\
\text { Variation }\end{array}$ & SS & Df & MS & $F$ & P-value & F crit \\
\hline $\begin{array}{l}\text { Between } \\
\text { Groups }\end{array}$ & 4544,823713 & 4 & 1136,206 & 33,02748 & $9,75 \mathrm{E}-06$ & 3,47805 \\
\hline $\begin{array}{l}\text { Within } \\
\text { Groups }\end{array}$ & 344,0183023 & 10 & 34,40183 & & & \\
\hline Total & 4888,842015 & 14 & & & & \\
\hline
\end{tabular}

Dapat dilihat pada tabel anova varian di bagian $P$-value menunjukan hasil 9,75E-06 atau bila ditulis dalam angka desimal nilainya sebesar $9,75 \times 10^{-6}$, hasil ini menunjukan adanya perbedaan yang signifikan terhadap kadar flavonoid yang terkandung dalam ekstrak propolis pada tiap-tiap $\mathrm{pH}$ karena nilai probabilitas $<0,05$

Pada pengamatan hasil uji efektivitas antimikroba terhadap bakteri Stapylococcus aureus, tampak zona hambatan pertumbuhan yang jernih sekitar difusi disk ekstrak propolis $\mathrm{pH} 8$. Sedangkan pada ekstrak propolis $\mathrm{pH} 2$, $\mathrm{pH} 4, \mathrm{pH}$ 6, dan $\mathrm{pH} 10$ tidak terlihat zona hambat yang terbentuk ( lihat Gambar 4 ).

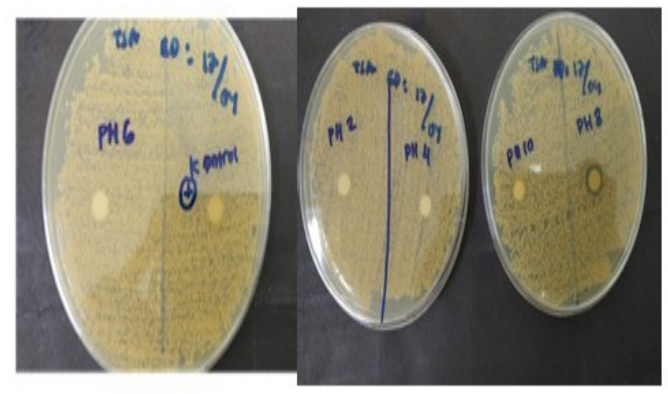

Gambar 4.Hasil uji antimikroba $\mathrm{pH}$ 2, $\mathrm{pH}$ 4, $\mathrm{pH} 6$ dan $\mathrm{pH} 10$

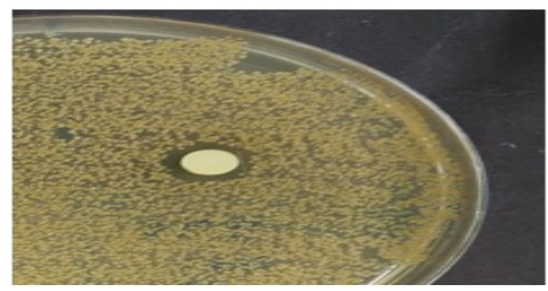

Gambar 5. Perbesaran hasil uji antimikroba $\mathrm{pH} 8$

Data perhitungan luas zona hambat dapat dilihat pada tabel 6 , pada ekstrak propolis $\mathrm{pH} 8$ terbentuk zona hambat sekitar 2,00 mm, ini menunjukan bahwa ekstraksi propolis menggunakan pelarut air $\mathrm{pH} 8$ efektif sebagai antimikroba, 
khususnya untuk mikroba Stapylococus aureus.

Tabel 6. Hasil uji aktifitas antimikroba propolis

\begin{tabular}{|c|c|}
\hline Sampel & Zona hambat (mm) \\
\hline $\mathrm{pH} 2$ & $0,00 \mathrm{~mm}$ \\
\hline $\mathrm{pH} 4$ & $0,00 \mathrm{~mm}$ \\
\hline $\mathrm{pH} 6$ & $0,00 \mathrm{~mm}$ \\
\hline $\mathrm{pH} 8$ & $2,00 \mathrm{~mm}$ \\
\hline $\mathrm{pH} 10$ & $0,00 \mathrm{~mm}$ \\
\hline
\end{tabular}

Namun bila kita lebih teliti melihat hasil uji antimikroba pada gambar diatas ada perbedaan antara kontrol positif dan sampel uji , dimana pada kontrol positif, disk yang ada di dalam media juga ditumbuhi bakteri sedangkan pada sampel uji bakteri hanya tumbuh di sekitar disk , ini menunjukan pada sampel uji yang lain pun ada daya antimikroba namun hanya sedikit sehingga tidak menghasilkan daya hambat.

Uji aktivitas antimikroba dilakukan dengan menggunakan difusi dicsk karena filtrat yang dihasilkan berupa cairan sehingga cara yang tepat dan mudah digunakan adalah cara difusi , hasil yang diperoleh dari penelitian uji aktifitas antimikroba yaitu pada ekstraksi propolis $\mathrm{pH} 8$ terbentuk zona hambat seluas 2.00 $\mathrm{mm}$ ini menandakan bahwa propolis memiliki daya antimikroba khususnya terhadap bakteri stappylococcus aureus. Namun bila kita lebih teliti melihat hasil uji antimikroba pada gambar diatas ada perbedaan antara kontrol positif dan sampel uji , dimana pada kontrol positif,disk yang ada di dalam media juga ditumbuhi bakteri sedangkan pada sampel uji,bakteri hanya tumbuh di sekitar disk , ini menunjukan pada sampel uji yang lain pun ada daya antimikroba namun hanya sedikit sehingga tidak menghasilkan daya hambat.

\section{SIMPULAN DAN SARAN}

Adapun kesimpulan dari hasil penelitian yaitu:

Variasi $\mathrm{pH}$ berpengaruh pada ekstraksi propolis. $\mathrm{pH}$ optimal untuk ekstraksi propolis menggunakan air terjadi pada $\mathrm{pH}$ 8. Hal tersebut dikarenakan penurunan polaritas air cukup signifikan. Pada pH 10 sehingga menyebabkan ada senyawa polar dalam propolis yang tidak bisa terekstrak dan menyebabkan kadar flavonoid menurun

Ekstrak propolis yang dihasilkan menunjukan daya antimikroba. Aktifitas antimikroba propolis terhadap bakteri stappylococcus aureus dapat terlihat pada ekstrak menggunakan air $\mathrm{pH} 8$ dengan luas zona hambat sebesar 2,00 mm .

\section{DAFTAR PUSTAKA}

Hasan, Akhmad E.Z., Mangunwidjaja, Djumali, 2013, Optimasi Ekstraksi Propolis Menggunakan Cara Maserasi Dengan Pelarut Etanol 70\% Dan Pemanasan Gelombang Mikro Serta Karakterisasinya Sebagai Bahan Antikanker Payudara, Jurnal Teknologi Industri Pertanian.

Kusuma, Sri A.F., 2009, Staphylococcus aureus, Universitas Padjadjaran Fakultas Farmasi.

Mello, Beatriz C.B.S. Kakuda, Paula M. , 2006 , Influence of $\mathrm{pH}$ variation during propolis extraction with the use of water as solvent. Dept. of Food Engineering, Faculty of Food Engineering, University of Campinas, Brazil.

Mihai, Cristina Manuela, Mărghita, Liviu Al., 2010, Estimation of Flavonoid Content in Propolis by Two Different Colorimetric Methods, Scientific Papers: Animal Science and Biotechnologies.

Mukhriani, 2011, Ekstraksi, Pemisahan Senyawa, Dan Identifikasi Senyawa Aktif. Program Studi Farmasi Fakultas IImu Kesehatan UIN Alauddin Makassar.

Paviani, Losiane C., Fiorito,Giulia, 2013, Different Solvents For Extraction Of Brazilian Green Propolis: Composition And Extraction Yield Of Phenolic Compounds.

Pujirahayu, Niken, Ritonga, 2014, Properties And Flavonoids Content In Propolis Of Some Extraction Method Of Raw Propolis, International Journal of Pharmacy and Pharmaceutical Sciences.

Waji, Resi Agestia, Sugrani, Andis , 2009. Flavonoid (Quercetine), Program S2 Kimia Fakultas Matematika dan IImu Pengetahuan Universitas Hasanuddin. 